\title{
CAMINHOS PERCORRIDOS POR GESTANTES E PUÉRPERAS NO SISTEMA PÚBLICO DE SAÚDE
}

\author{
PATHWAYS TRAVELED BY PREGNANT AND \\ PREGNANT WOMEN IN THE PUBLIC HEALTH SYSTEM
}

\author{
Carolina Araújo Londero ${ }^{1}$ e Martha Souza ${ }^{2}$
}

\section{RESUMO}

A presente pesquisa teve por objetivo conhecer os caminhos percorridos por gestantes e puérperas na rede de atendimento do Sistema Único de Saúde (SUS), de um município da região central do Rio Grande do Sul - RS, bem como fortalecer o debate acerca das políticas públicas para o cuidado de gestantes e puérperas na rede do SUS. Para isso, realizou-se uma pesquisa descritiva, exploratória e de caráter qualitativo, no período de Outubro a Dezembro de 2019, com doze mulheres entre 18 e 30 anos de idade. Para a discussão dos dados, os relatos foram divididos em duas categorias de análise: a) o cuidado de enfermagem durante a gestação e, b) o espaço público no caminho do cuidado à saúde. Esse trabalho evidenciou que, em sua maioria, as mulheres realizaram o pré-natal nas Unidades Básicas de Saúde (UBS) próximas de sua moradia e, nesses espaços, elas identificaram como de fundamental importância o papel do enfermeiro para o cuidado.

Palavras-chave: Mulheres; Enfermagem; SUS.

\section{ABSTRACT}

The present research aimed to know the paths taken by pregnant women and puerperal women in the service network of the Unified Health System of a city in the central region of Rio Grande do Sul, as well as to strengthen the debate about public policies for the care of pregnant women and puerperal women. In the SUS network. It was carried out by means of qualitative exploratory descriptive research from October to December 2019 with twelve women aged between 18 and 30 years. The reports were divided into two categories, namely: nursing care during pregnancy and the public space in the path of health care. This study identified that, for the most part, women underwent prenatal care in Basic Health Units close to their home. In these spaces, they identified the role of nurses for care as of fundamental importance.

Keywords: Women; Nursing; SUS.

\footnotetext{
${ }^{1}$ Autora. Acadêmica Enfermagem/Universidade Franciscana, bolsista FAPERGS. E-mail: carolina.alondero@gmail.com

${ }^{2}$ Orientadora. Docente do curso de Enfermagem da Universidade Franciscana. E-mail:marthahts@gmail.com
} 


\section{INTRODUÇÃO}

A construção dos percursos de cuidado em saúde nos coloca diante de um contexto de mudanças e desafios provocados pela consolidação do Sistema Único de Saúde (SUS), sua manutenção e aprimoramento. Nesse sentido, faz-se necessário a incorporação de novos recursos, capazes de contribuírem com a construção e formulação de propostas de intervenções que sejam centradas no indivíduo e que possam considerar sua interação com seu contexto e história de vida (MÂNGIA, MURAMOTO, 2008). Além disso, ressalta-se que o conhecimento sobre os trajetos de pessoas em busca de atenção à saúde pode contribuir para compreensão sobre o comportamento em relação ao cuidado e utilização de serviços de saúde (CABRAL et al., 2011).

Essa pesquisa justifica-se pela importância da compreensão dos caminhos percorridos por gestantes e puérperas em busca de atenção aos seus problemas de saúde, visando superar o modelo biomédico, seus limites e a necessidade de superação desse paradigma. Percebe-se que efetivar um cuidado de qualidade permanece sendo um dos maiores desafios e objetivos da saúde no Brasil. Para incrementar essa realidade, é imprescindível que os serviços e profissionais de saúde acolham com dignidade a mulher e o recém-nascido, enfocando-os como sujeitos de direitos. Nesse sentido, considerar o outro como sujeito e não como objeto passivo da nossa atenção integra a base que sustenta o processo de humanização (BRASIL, 2005).

Em relação ao cuidado com a saúde de gestantes e puérperas, foi lançado, no ano de 2000, o Programa de Humanização no Pré-natal e Nascimento (PHPN). Os elementos estruturadores desse programa foram a humanização e o respeito aos direitos reprodutivos, com o objetivo principal de reduzir a morbimortalidade materna e neonatal (BRASIL, 2005).

Apesar dessa iniciativa, permaneceram grandes desafios a serem superados na qualidade da assistência e da atenção integral à saúde das gestantes e puérperas e, por isso, considera-se igualmente importante a observação de aspectos psicológicos, emocionais e culturais que envolvem essa assistência (BRASIL, 2014).

Com a intenção de ampliar o acesso e melhorar a qualidade de atenção pré-natal, o Ministério da Saúde lançou, no ano de 2011, a Rede Cegonha (BRASIL, 2011), que prevê ações como a garantia do acompanhante, indicado pela mulher na sala de parto, implementação de boas práticas durante o parto e nascimento, a ligação da gestante à unidade de referência e o incentivo ao aleitamento materno (SANTOS, MELO, CRUZ 2015).

Frente ao exposto, questiona-se: quais caminhos percorridos pelas gestantes e puérperas na rede pública para seu atendimento? E, a partir desse questionamento, a presente pesquisa teve como objetivo conhecer os caminhos percorridos por gestantes e puérperas na rede de atendimento do Sistema Único 
de Saúde (SUS) de um Município da região central do Rio Grande do Sul - RS, bem como fortalecer o debate acerca das políticas públicas para o cuidado de gestantes e puérperas na rede do SUS.

\section{MATERIAL E MÉTODOS}

Essa pesquisa foi aprovada pelo Comitê de Ética em Pesquisa com Seres Humanos da Universidade Franciscana, sob o número 3.466.563, conforme Resolução no. 466/2012 e trata-se de estudo de abordagem qualitativa, exploratória e de caráter descritivo, realizado em um hospital de médio porte em um Município da região central do Rio Grande do Sul -RS, no período de Outubro a Dezembro de 2019. A pesquisa qualitativa considera aspectos complexos e profundos inerentes às relações humanas, que são percebidos no cotidiano, na vivência das pessoas e na explicação do senso comum e das questões empíricas (MINAYO, 2010).

Fizeram parte desse estudo quatro gestantes e oito puérperas, que se encaixavam dentro dos dois critérios de inclusão, que foram estabelecido para o estudo: a) ser maiores de 18 anos e, b) estar gestante ou vivendo o período de puerpério. Ainda, vale destacar que foram excluídas as mulheres que apresentavam algum problema de saúde durante o período de coleta de dados e, após esclarecimento de todas as dúvidas, as participantes assinaram o Termo de Consentimento Livre e Esclarecido e foram entrevistadas individualmente. Para resguardar o anonimato, a identificação das interlocutoras foi feita a partir das iniciais G (Gestantes) e P (Puérperas), seguidas do número de entrada na ordem do texto.

A pesquisa desenvolveu-se em um hospital público de uma cidade de médio porte na região central do Rio Grande do Sul - RS, e foram convidadas a participar desse estudo as gestantes e as puérperas sob acompanhamento nesse serviço público.

As respostas foram gravadas e, após, transcritas, utilizou-se a técnica de análise temática, seguindo as fases de pré-análise, exploração do material, tratamento dos resultados obtidos e interpretação (MINAYO, 2010), para a análise dos dados obtidos, a partir das entrevistas realizadas com as participantes.

\section{RESULTADOS E DISCUSSÕES}

Ao todo, participaram da pesquisa doze mulheres, sendo quatro gestantes e oito puérperas entre 18 e 30 anos. Salienta-se que, das entrevistadas, seis eram primigestas. A escolaridade predominante foi o ensino fundamental completo.

A partir dos resultados, obteve-se duas categorias de análise, sendo elas: a) o cuidado de enfermagem durante a gestação e, b) o Sistema Único de Saúde no caminho do cuidado. Dessa maneira, essas categorias serão discutidas a seguir. 


\section{$O$ cuidado de enfermagem durante a gestação}

As gestantes entrevistadas revelaram que buscaram a Unidade de Saúde mais próxima da sua casa para a realização do pré-natal, tendo encontrado, nesses espaços, o cuidado de enfermagem, como pode-se observar nas falas abaixo transcritas:

"quando a menstruação atrasou já fui na UBS aqui pertinho. A enfermeira encaminhou para o teste e deu positivo. Ela já foi marcando as consultas e falou de um grupo que acontece todos os meses para falar sobre o que acontece com a gente quando estamos esperando bebê. Para mim foi bem importante, pois era primeiro filho e eu estava bem ansiosa" (G2)

"toda vez que eu ia no posto a enfermeira estava lá e eu consultava com ela. O médico, nem sempre aparecia. Então posso dizer que foi ela quem fez meu pré-natal. Depois, no hospital as enfermeiras estavam lá de novo. Me ajudaram na hora de nascer, apesar que a enfermeira do posto já tinha falado como acontecia e isso diminuiu um pouco o medo" (G4)

Os relatos acima salientam a importância do(a) enfermeiro(a) na atenção à gestante e, assim, destaca-se que o cuidado durante o pré-natal deve ser realizado de forma integral dispondo de profissionais competentes e dedicados oferecendo assistência adequada nesse período (DOURADO, PELLOSO, 2007).

Durante a gestação, ocorrem transformações físicas, que fazem parte do processo do desenvolvimento humano, e é importante lembrar que elas não ocorrem só no organismo da mulher, mas socialmente também, com isso a importância de um atendimento integral a está gestante (FALCONE et al., 2004).

O SUS preconiza que o usuário seja atendido respeitando os princípios da integralidade, universalidade e equidade (BRASIL, 2005) e, nesse contexto, as consultas de enfermagem representam um espaço que prioriza esses princípios, por meio da comunicação com as gestantes, visto que promovem o diálogo com as usuárias, permitindo a expressão de experiências, sentimentos, anseios e resolução de dúvidas advindas desta fase. Além disso, a escuta e o diálogo facilitam o vínculo entre a gestante e a enfermeira, o que é determinante para que haja um atendimento humanizado (GRANDO et al., 2012).

Vale ressaltar que, visando o melhor atendimento do período gravídico-puerperal, o Ministério da Saúde instituiu a Política de Humanização do Pré-Natal e Nascimento, cujo objetivo é garantir para a gestante acesso e qualidade durante o acompanhamento pré-natal (BRASIL, 2000).

No atendimento humanizado, o enfermeiro tem lugar de destaque na equipe, pois é um profissional apto para atender a mulher, desempenhando um papel de extrema importância na área de prevenção e de promoção da saúde, além de ser um agente de educação. Durante a gestação, ocorrem alterações que envolvem todos os sistemas orgânicos, gerando expectativa, comoção, angústia, preocupação e descobertas sendo necessário conhecer todas essas transformações para que se preste um auxílio adequado à saúde da gestante (MARTINS et al., 2015). 
Salienta-se que o Programa de Humanização do Parto e Nascimento (PHPN) parte do pressuposto de que a melhoria do acesso e da qualidade do acompanhamento de pré-natal é importante para a redução das altas taxas de morbimortalidade materno-infantil registradas no Brasil (BRASIL, 2000).

\section{O Sistema Único de Saúde no caminho do cuidado}

A assistência pré-natal e período de puerpério compreendem um conjunto de ações que tem por objetivo prevenir, diagnosticar e tratar eventos indesejáveis à gestante, ao parto e ao recém-nascido. Quando realizado de forma efetiva é capaz de diminuir a morbidade e a mortalidade materno-infantil (PEREIRA et al., 2017).

Nas falas das entrevistadas, percebe-se o reconhecimento delas quanto ao atendimento ofertado pela equipe do SUS, conforme relatos abaixo.

\footnotetext{
"Vejo muita gente que fala mal do SUS. Tive dúvidas se eu ia na unidade perto da minha casa. Mas no primeiro dia que fui lá a enfermeira já me encaminhou para participar de um grupo de gestantes. Foi ótimo" (P6)

"Desde que engravidei eu via na televisão que o SUS não presta, não atende bem. Então eu tinha medo. Muito medo de não conseguir consulta ou de ser mal atendida. Mas depois que fui no posto e no hospital, deu tudo certo. E foi tudo pelo SUS" (P10)
}

Ao analisar as falas, percebe-se que, muitas vezes, as pessoas buscam o serviço de saúde com alguns pré-conceitos já estabelecidos, entre eles, destaca-se a ineficiência do SUS. Entretanto, o direito de uma assistência à saúde foi firmado na Constituição Federal de 1988, com a construção de um sistema de saúde, que tem como base a descentralização do cuidado, a participação dos usuários por meio dos Conselhos e Conferências Municipais de Saúde, visando a formulação, implantação, controle e avaliação das políticas de saúde (BRASIL, 2011).

O acompanhamento pré-natal e o cuidado com a parturiente são ações fundamentais para prevenção de patologias, impactando de maneira positiva nos indicadores de saúde materno-infantis. Assim, o principal objetivo da atenção pré-natal e puerperal é acolher a mulher desde o início da gravidez, assegurando fim da gestação, nascimento de criança saudável e garantia do bem-estar materno e neonatal (AMORIM, MOREIRA, OLIVEIRA, 2017).

Com base nos debates acerca da ampliação dos direitos das mulheres, no ano de 2004, o Ministério da Saúde promulgou a Política Nacional de Atenção Integral à Saúde da Mulher (PNAISM), consolidando e organizando as ações voltadas ao cuidado de gestantes e puérperas no âmbito do SUS. O documento do PNAISM incorpora a integralidade e a promoção da saúde como princípios norteadores para atender às necessidades de saúde da mulher, de forma abrangente, humanizada e hierarquizada (BRASIL, 2016).

Com o objetivo de melhorar a assistência a essas mulheres, foi lançada, em 2011, a Rede Cegonha, adotando medidas que assegurem a melhoria do acesso, da cobertura e da qualidade 
do acompanhamento pré-natal, da assistência ao parto e puerpério e da assistência à criança (BRASIL, 2011).

A Rede Cegonha ainda prevê a qualificação dos profissionais de saúde, bem como a criação de Casa da Gestante e a Casa do Bebê, e os Centros de Parto Normal, estas ações contribuem para a saúde da mulher na concepção, contracepção e durante o ciclo gravídico-puerperal (MAMEDE et al., 2015). Com a consolidação desta política pública, o atendimento é resolutivo e integral, conforme previsto na Lei $n^{\circ}$. 8.080/1990, vale ressaltar que, com essa política pública, o recém-nascido tem acompanhamento até os dois anos de idade.

\section{CONSIDERAÇÕES FINAIS}

A fim de conhecer os caminhos percorridos por gestantes e puérperas na rede de atendimento do Sistema Único de Saúde de um Município da região central do Rio Grande do Sul -RS, percebeu-se que essas usuárias consideraram os serviços adequados.

Além disso, esse trabalho buscou fortalecer o debate acerca das políticas públicas para o cuidado de gestantes e puérperas nos serviços públicos de saúde, contribuindo para reflexões sobre a estruturação, organização e qualificação da rede de atenção integral à saúde, promovendo acesso com acolhimento e resolutividade, em consonância com as políticas de saúde.

Sugere-se, ainda, a realização de novas pesquisas, que discutem o cuidado dessa população nos serviços de saúde, tendo em vista a consolidação de políticas já existentes, bem como fomentar a necessidade de novas demandas. Contudo, há muito para ser desenvolvido e aperfeiçoado, mas se pode afirmar que as políticas públicas brasileiras buscam o cuidado integral de toda a população.

\section{REFERÊNCIAS}

AMORIM FCM, NEVES ACN, MOREIRA FS, OLIVEIRA ADS, Nery IS. Profile of pregnant women with pre-eclampsia. Revista de Enfermagem UFPE on line. 2017. 11(4):1574-83.

BRASIL. Ministério da Saúde. Secretaria de Políticas de Saúde. Programa de humanização no pré-natal e nascimento. Brasília, 2000.

BRASIL. Ministério da Saúde. Secretaria de Atenção à Saúde. Departamento de Ações Programáticas Estratégicas. Área Técnica de Saúde da Mulher. Pré-natal e Puerpério: atenção qualificada e humanizada - manual ténico/Ministério da Saúde, Secretaria de Atenção à Saúde, Departamento de Ações Programáticas Estratégicas - Brasília: Ministério da Saúde, 2005. 158 p. color. - (Série A. Normas e Manuais Técnicos) - (Série Direitos Sexuais e Direitos Reprodutivos - Caderno no 5). 
BRASIL. Ministério da Saúde (BR). Secretaria de Atenção à Saúde. Departamento de Ações Programáticas Estratégicas. Política Nacional de Atenção Integral à Saúde da Mulher: Princípios e Diretrizes. / Ministério da Saúde, Secretaria de Atenção à Saúde, Departamento de Ações Programáticas Estratégicas. - 1. ed., 2. reimpr. Brasília, 2011. Disponível em: https://bit.ly/3pczILe

BRASIL. Ministério da Saúde (BR). Humanização do parto e do nascimento. (Cadernos HumanizaSUS; v. 4). Brasília: Ministério da Saúde; 2014. Disponível em: https://bit.ly/3sMP6QG

BRASIL. Ministério da Saúde. Secretaria de Políticas para as Mulheres - SPM, Monitoramento e Acompanhamento da Política Nacional de Atenção Integral à Saúde da Mulher (PNAISM) e do Plano Nacional de Políticas para as Mulheres 2013-2015 (PNPM), 2016.

CABRAL, ALLV; MARTINEZ-HEMAEZ, A; ANDRADE, EIG; CHERCHIGLIA, ML. Itinerários terapêuticos: o estado da arte da produção científica no Brasil. Ciência e saúde coletiva [online]. 2011, v. 16, n. 11.

CASSIANO, A. C. M. et al. Saúde materno infantil no Brasil: evolução e programas desenvolvidos pelo Ministério da Saúde. Revista do Serviço Público, Brasília, v. 65, n. 2, p. 227-244, jun. 2014.

DOURADO, VG; PELLOSO, SM. Gravidez de alto risco: o desejo e a programação de uma gestação. Acta Paul. Enferm. 2007;20(1):69-74.

GRANDO, T; MELLO, SM; FONTANA, R; RODRIGUES, FCP. Consulta pré-natal: satisfação das usuárias do SUS. Cogitare Enfermagem. 2012, 17(2), 336-341. Disponível em https://bit.ly/2NtqPz6

MAMEDE, FV; PRUDÊNCIO, PS. Contribuições de programas e políticas públicas para a melhora da saúde materna. Revista Gaúcha de Enfermagem. 2015;36(esp):262-6.

MÂNGIA, E. F.; MURAMOTO, M. T. Itinerários terapêuticos e construção de projetos terapêuticos cuidadores. Rev. Ter. Ocup. Univ. São Paulo, v. 19, n. 3, p. 176-182, set./dez. 2008.

MARTINS, QMP; FERREIRA, GMS; ARAGÃO, AA; GOMES, FM; ARAÚJO, LM; FERREIRA, FS. Conhecimentos de gestantes no pré-natal: evidências para o cuidado de enfermagem. SanareRevista de Políticas Públicas. Sobral, v. 14, n. 02, p. 65-71, jul./dez, 2015.

MINAYO, MCS. Desafio do conhecimento. 14. ed. São Paulo (SP): Hucitec-Abrasco; 2014. 
OLIVEIRA, SC; FERREIRA, JG; SILVA, PP; FERREIRA, JM; SEABRA, RA; FERNANDO, VC. A participação do homem/pai no acompanhamento da assistência pré-natal. Cogitare Enfermagem; 2009 Jan/Mar.

PEREIRA, RCA; RIVERA, FJ; ARTMANN, E. O trabalho multiprofissional na estratégia saúde da família: estudo sobre modalidades de equipes. Rio Janeiro, 2013.

SANTOS, RAA; MELO, MCP; CRUZ, DD. Trajetória de humanização do parto no Brasil a partir de uma revisão integrativa de literatura. Caderno de Cultura e Ciência [internet]. 2015. 